\title{
MUSKINGUM AND LAG METHOD RIVER ROUTING PARAMETERS FOR KLANG RIVER AT KUALA LUMPUR CITY CENTRE DERIVED USING RECORDED HYDROGRAPHS
}

\author{
(Date received: 19.09.2018/Date accepted: 15.02.2019)
}

\author{
Jer Lang Hong ${ }^{1}$, Suzana Shafie², Irena Naubi², Siew Fang Yong ${ }^{2}$, and Kee An Hong ${ }^{1}$
}

${ }^{1}$ Hong and Associates, ${ }^{2} G \& P$ Water \& Maritime Sdn. Bhd.

Email: jerlang.hong@taylors.edu.my, suzana_peace@yahoo.com,irena.naubi@gmail.com,siewfang_yong@yahoo.com, keeanhong@yahoo.co.uk

\begin{abstract}
In this Study, the Muskingum and Lag river routing models were used to estimate the routing coefficients of Klang river using flood records of gauging stations at Leboh Pasar and Sulaiman Bridge, for a river reach of $900 \mathrm{~m}$ between the two gauging stations. Recorded inflow hydrographs at Leboh Pasar and outflow hydrographs at Suilaman Bridge were used to calibrate and validate the Muskingum and Lag routing models. Best fit routing parameters for the models were derived using the optimization module of HEC-HMS, and the average parameters obtained were used to validate the routing models using different sets of flood events. The outflow hydrographs at Sulaiman Bridge derived from routing models were used to compare with the observed hydrographs by plotting the hydrographs for visual inspections. The ability to produce the observed flow at the Sulaiman Bridge by the routing models were also assessed statistically by calculating the goodness of fit indices from the routed and observed hydrographs. Graphical inspections of routed and observed hydrographs show that the Muskingum and lag models give congruent results in estimating the outflow at Sulaiman Bridge. The results obtained are also in good agreement with the observed flows. However, the goodness of fit indices show that the Muskingum model overall gives a better fit than the Lag method.
\end{abstract}

Keywords: Calibration, Lag, MSE, Muskingum, NSE, RMSE, Routing, Validation

\subsection{INTRODUCTION}

In a river reach or reservoir, a procedure used to predict the temporal and spatial variations of a flood hydrograph moving through it is flood routing. As the flood wave moves from an upstream to a downstream point, changes in hydrograph shape and timing due to the routing effects such as storage and flow resistance within a river reach can be clearly seen. In general, routing techniques may be classified into two categories: hydraulic routing, and hydrologic routing. Hydraulic routing techniques are based on the solution of the partial differential equations of unsteady open channel flow. These equations are often referred to as the St. Venant equations or the dynamic wave equations. Hydrologic routing employs the continuity equation and an analytical or an empirical relationship between storage within the reach and discharge at the outlet.

Flood forecasting, reservoir and channel design, floodplain studies, and watershed simulations generally utilize some form of routing. Typically, in watershed simulation studies, hydrologic routing is utilized on a reach-by-reach basis from upstream to downstream. For example, it is often necessary to obtain a discharge hydrograph at a point downstream from a location where a hydrograph has been observed or computed. For such purposes, the upstream hydrograph is routed through the reach with a hydrologic routing technique that predicts changes in hydrograph shape and timing. Local flows are then added at the downstream location to obtain the total flow hydrograph.
This type of approach is adequate as long as there are no significant backwater effects or discontinuities in the water surface because of jumps or bores. When there are downstream controls that will have an effect on the routing process through an upstream reach, the channel configuration should be treated as one continuous system. This can only be accomplished with a hydraulic routing technique that can incorporate backwater effects as well as internal boundary conditions, such as those associated with culverts, bridges, and weirs.

This paper focused on storage routing, involving solution of the equation of continuity (or conservation of mass), often referred to as storage equation. Storage routing considers the effect of storage on the hydrograph, including translation or delay of the peak, and attenuation or reduction of the hydrograph. The change in magnitude of the hydrograph in respect to the two aspects mentioned depends on the volume of flood relative to the volume of storage through which the flood passes and the physical characteristics of the storage such as length, shape slope and hydraulic resistance of the reach. In this context, storage is the volume of water temporarily stored within the reach at any given time and the water is in transit to the outlet of the downstream end.

As storage is temporarily, the total volume of outflow must equal the volume of inflow, and this should be checked in all routing calculations. For the great majority of problems, solutions based on the storage equation are quite satisfactorily. 


\subsection{Hydrologic Routing Techniques}

Hydrologic routing employs the use of the continuity equation and either an analytical or an empirical relationship between storage within the reach and discharge at the outlet. In its simplest form, the continuity equation can be written as inflow minus outflow equals the rate of change of storage within the reach:

$$
I-O=\frac{\Delta S}{\Delta t}
$$

where

$I=$ the average inflow to the reach during $\Delta \mathrm{t}$

$O=$ the average outflow from the reach during $\Delta \mathrm{t}$

$S=$ storage within the reach

Hydrologic routing techniques have been widely applied to solve river routing problems, for example, more commonly used methods are kinematic wave routing, Muskingum routing, lag routing, Muskingum Cunge routing, modified Puls routing, straddle stagger routing as listed in HEC-HMS[1]. The numerical implementation of the kinematic wave approximation is usually the Muskingum or the Cunge Muskingum method [2]. This method has been, since its inception, the method of choice in most flood routing application because of its computational expediency. Numerous research of the last decades has been devoted to the problem of determining the proper routing coefficients of the Muskingum method, using information of stream channel characteristics or the calibration of observed flood hydrographs. Gill[3] used linear least squares to determine the unknown parameters in the prism/wedge storage term which is the basis of the Muskingum method. Mohan[4] applied a genetic algorithm to estimate the parameters in a nonlinear Muskingum model. Tayfur and Moramarco[5] developed an artificial neural network (ANN) to forecast flood waves in the upper Tiber river in Italy. The ANN method has also been applied by Hong and Hong [6] for flood forecasting for Klang river. Oladghafari[7] determined the routing parameters of the Muskingum model for 3 flood events in a reach of the Mchranrood in Iran by the classical procedure. Zare and Koch[8] use nonlinear programming and multiple linear regression methods to optimize the the routing coefficients.

The above discussion shows that research on Muskingum and other river routing is still active. That is, the determination of the optimal routing coefficients in the Muskingum model in application is still in progress. Examples of recent researches on Muskingum method are Ansari and Ukarnde [9], Song and Kong [10], Kumar and Raju [11], Elbashir [12], Reggiani et al., [13], Sujikumar and Suman [14] Tewolde and Smithers [15].

In this Paper, calculation of river routing for Klang river is based on the inflow and outflow of observed floods adjusted to equal volumes within the selected period of analysis. The study river reach is $950 \mathrm{~m}$ from an upstream inflow site (gauging station, Klang river at Leboh Pasar) to the downstream site (gauging station, Klang river at Sulaiman Bridge). Two commonly used hydrologic routing methods are adopted for analysis, namely the Muskingum and the Lag method. Recorded flood hydrographs of the two gauging stations were used to estimate the model parameters of the two routing methods using the optimization module of the HEC-HMS program [1].

\subsection{MATERIALS AND METHODS}

The following sections present the details of floods chosen for analysis and the methods used in river routing for the Klang river.

\subsection{Flood Hydrographs of Klang River}

In this study, Klang river with two gauging stations with a reach of about $950 \mathrm{~m}$ apart was selected as a case study. The main aim is to derive the routing parameters of the Muskingum and Lag models of the study reach using recorded hydrographs of the two gauging stations. The work includes the estimation of routing parameters using recorded flood hydrographs and HEC-HMS computer program [1] to calibrate the routing models. After successful calibration, verification runs using different sets of floods recorded are carried out for model accuracy assessment. Details of the study river reach, inflow site (Leboh Pasar gauging station) and outflow site (Sulaiman Bridge gauging station) are shown in Figure 1. Concurrent discharge data are available from the automatic recorders from these stations from October 1973 to December 1974. Details of the gauging stations and records available are shown in Table 1. Examination of the flow records shows that several flood events in this period are available and can be adopted for river routing analysis. Selected flood events used in this study are shown in Table 2.

Table 1: Details of the gauging records

\begin{tabular}{|c|c|c|c|}
\hline $\begin{array}{c}\text { Station } \\
\text { ID }\end{array}$ & Station Name & Period of Record & $\begin{array}{c}\text { Catchment } \\
\text { Area } \mathbf{( k m}^{\mathbf{2}}\end{array}$ \\
\hline 3116432 & $\begin{array}{c}\text { Klang at Leboh Pasar } \\
\text { Kuala Lumpur }\end{array}$ & Jul 1960 - Dec 1974 & 464 \\
\hline 3116430 & Klang at Sulaiman Bridge & Oct 1973 - to date & 468 \\
\hline
\end{tabular}

Table 2: Selected floods used for routing analysis

\begin{tabular}{|c|c|c|c|}
\hline \multirow{2}{*}{$\begin{array}{l}\text { Flood } \\
\text { Event }\end{array}$} & \multicolumn{3}{|c|}{ Peak Flow $\left(\mathbf{m}^{3} / \mathbf{s}\right)$} \\
& & \multicolumn{2}{|c|}{} \\
\cline { 2 - 4 } & & $\begin{array}{c}\text { at Leboh } \\
\text { Pasar }\end{array}$ & $\begin{array}{c}\text { at Sulaiman } \\
\text { Bridge }\end{array}$ \\
\hline 1 & $06 / 12 / 197318: 00$ to $11 / 12 / 197310: 00$ & 191.2 & 151.3 \\
\hline 2 & $22 / 12 / 197310: 00$ to $24 / 12 / 197320: 30$ & 75.5 & 75.7 \\
\hline 3 & $24 / 11 / 197313: 00$ to $27 / 11 / 197316: 00$ & 110.9 & 93.6 \\
\hline 4 & $02 / 05 / 197415: 00$ to $03 / 05 / 197419: 00$ & 63.5 & 63.8 \\
\hline 5 & $07 / 12 / 197412: 00$ to $10 / 12 / 197404: 00$ & 56.4 & 53.9 \\
\hline 6 & $10 / 12 / 197410: 00$ to $13 / 12 / 197407: 00$ & 69.3 & 70.8 \\
\hline
\end{tabular}

As the area between the gauging stations is small and no tributaries enter the reach between the stations, the runoff volume of inflow hydrograph should equal that of outflow hydrograph. Therefore, within the analysis period, if the outflow runoff volume is found to be higher than the inflow volume, the inflow hydrograph was scaled proportionally so that the volume of flow at upstream side is equal to that of downstream as there are no records available for local inflow. The start and end times for the analysis are selected so that average discharges in the reach were approximately equal in the start and end time of the hydrographs. Figure 2 and Figure 3 show two of the selected flood hydrographs recorded at the gauging stations. 


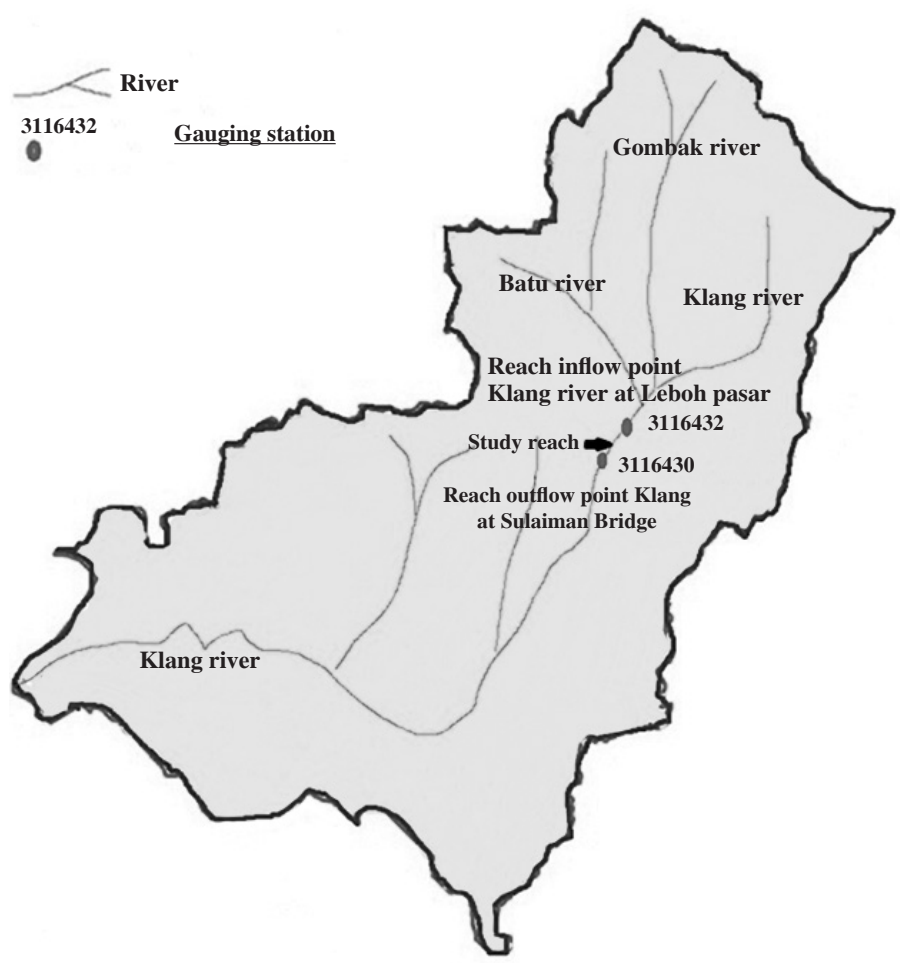

Figure 1: Study channel reach and inflow/outflow locations for Klang river

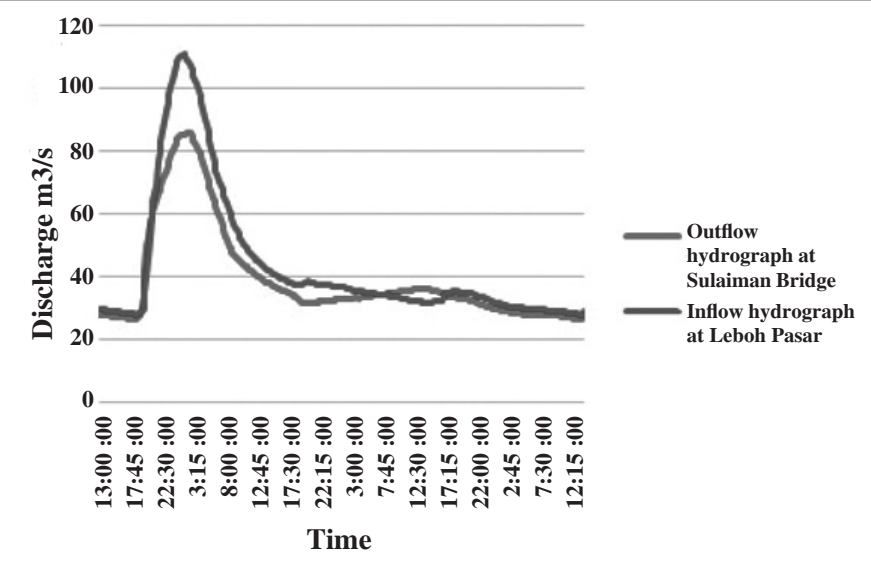

Figure 2: Recorded inflow and outflow hydrographs of Klang river at the study reach occurred on 24/11/1973

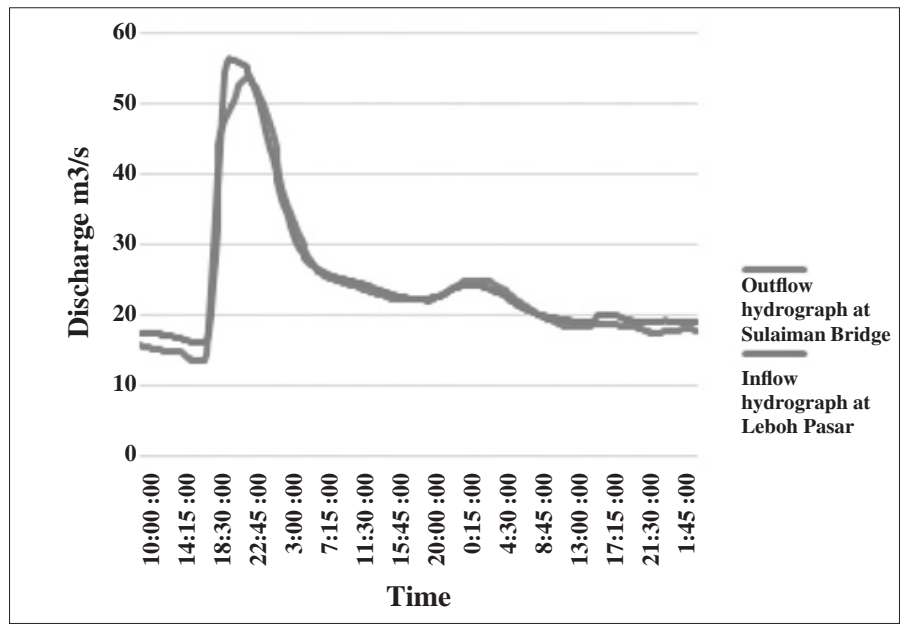

Figure 3: Recorded inflow and outflow hydrographs of Klang river at the study reach occurred on 07/12/1974

\subsection{Muskingum Method}

The Muskingum method was developed to directly accommodate the looped relationship between storage and outflow that exists in rivers. With the Muskingum method, storage within a reach is visualized in two parts: prism storage and wedge storage. Prism storage is essentially the storage under the steady flow water surface profile. Wedge storage is the additional storage under the actual water surface profile. As shown in Figure 4, during the rising stages of the flood wave the wedge storage is positive and added to the prism storage. During the falling stages of a flood wave, the wedge storage is negative and subtracted from the prism storage.

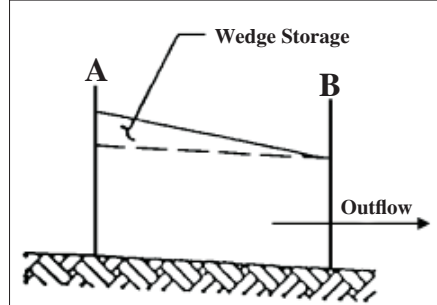

(a)

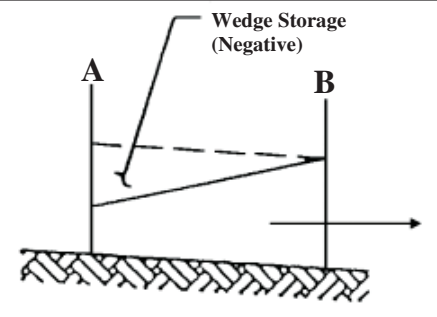

(b)
Figure 4: Muskingum prism and wedge storage concept

\subsubsection{The Muskingum Routing Equation}

Prism storage is computed as the outflow $(O)$ times the travel time through the reach $(K)$. Wedge storage is computed as the difference between inflow and outflow $(I-O)$ times a weighting coefficient $x$ and the travel time $K$. The coefficient $K$ corresponds to the travel time of the floodwave through the reach. The parameter $\mathbf{x}$ is a dimensionless value expressing a weighting of the relative effects of inflow and outflow on the storage $(S)$ within the reach. Thus, the Muskingum method defines the storage in the reach as a linear function of weighted inflow and outflow:

$$
\begin{aligned}
& S=\text { prism storage }+ \text { wedge storage } \\
& S=K O+K x(I O) \\
& S=K[x I(1-x) O]
\end{aligned}
$$

where

$S=$ total storage in the routing reach

$\mathrm{O}=$ rate of outflow from the routing reach

$I=$ rate of inflow to the routing reach

$K=$ travel time of the floodwave through the reach

$x=$ dimensionless weighting factor, ranging from 0.0 to 0.5

The quantity in the brackets of Equation 2 is considered an expression of weighted discharge. When $\mathrm{x}=0.0$, the equation reduces to $S=K O$, indicating that storage is only a function of outflow, which is equivalent to level-pool reservoir routing with storage as a linear function of outflow. When $x=0.5$, equal weight is given to inflow and outflow, and the condition is equivalent to a uniformly progressive wave that does not attenuate. Thus, "0.0" and " 0.5 " are limits on the value of $x$, and within this range the value of $x$ determines the degree of attenuation of the flood wave as it passes through the routing reach. A value of " 0.0 " produces maximum attenuation, and " 0.5 " produces pure translation with no attenuation.

The routing period $\Delta t$ of the Muskingum method should be rounded off to an even interval for ease of calculation, and should 
be selected to conform generally with the following conditions:

$\Delta \mathrm{t}<=0.2 \mathrm{~T}_{\mathrm{R}}$

Where $T_{R}$ is the time of rise of the inflow hydrograph

$\Delta \mathrm{t}<=\mathrm{K}$

$\Delta \mathrm{t}>=2 \mathrm{Kx}$

\subsection{Lag Model}

This is the simplest of the routing models. With it, the outflow hydrograph is simply the inflow hydrograph, but with all ordinates translated (lagged in time) by a specified duration. The flows are not attenuated, so the shape is not changed. This model is widely used, especially in urban drainage channels [16].

Mathematically, the downstream ordinates are computed by:

$$
\mathrm{O}_{\mathrm{t}}=\left\{\begin{array}{lll} 
& \mathrm{I}_{\mathrm{t}} & \mathrm{t}<\mathrm{lag} \\
& \mathrm{I}_{\mathrm{t}-\mathrm{lag}} & \mathrm{t}>=\mathrm{lag}
\end{array}\right.
$$

where

$\mathrm{Ot}=$ outflow hydrograph ordinate at time

$\mathrm{I}_{\mathrm{t}}=$ inflow hydrograph ordinate at time $\mathrm{t}$; and

lag = time by which the inflow ordinates are to be

lagged.

Figure 5 illustrates the results of application of the lag model. In the figure, the upstream (inflow) hydrograph is the boundary condition. The downstream hydrograph is the computed outflow, with each ordinate equal to an earlier inflow ordinate, but lagged in time.

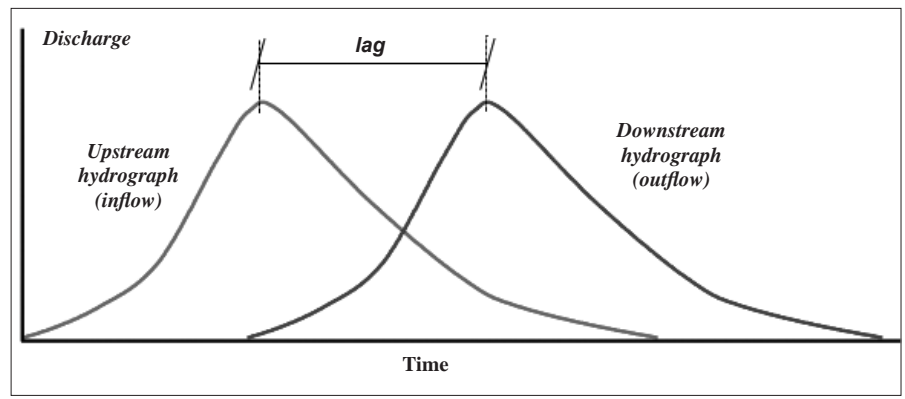

Figure 5: Lag model example

The lag model is a special case of other models, as its results can be duplicated if parameters of those other models are carefully chosen. For example, if $\mathrm{X}=0.50$ and $\mathrm{K}=\Delta \mathrm{t}$ in the Muskingum model, the computed outflow hydrograph will equal the inflow hydrograph lagged by $\mathrm{K}$.

\subsubsection{Estimating The Lag}

If observed flow hydrographs are available, the lag can be estimated from these as the elapsed time between the time of the centroid of areas of the two hydrographs, between the time of hydrograph peaks, or between the time of the midpoints of the rising limbs.

\subsection{Calibration of Routing Models Using HEC- HMS}

The river routing models consist of parameters that must be specified in order to use the model for estimating runoff or routing hydrographs. For the routing models, appropriate values for the parameters can be selected if streamflow observations are available, by model calibration. Calibration uses observed hydrometeorological data in a systematic search for parameters that yield the best fit of the computed results to the observed runoff. This search is often referred to as optimization. In this Paper, HEC-HMS of Hydrologic Engineering Centre [1] is adopted for this purpose.

\subsubsection{Calibration Procedure}

In HEC-HMS, the systematic search for the best (optimal) parameter values begins with data collection. For routing models, observations of both inflow to and outflow from the routing reach are required. Table 3 offers some tips for collecting these data.

Table 3: Tips for collecting data for routing model calibration

The upstream and downstream hydrograph time series must represent flow for the same period of time.

The volume of the upstream hydrograph should approximately equal the volume of the downstream hydrograph, with minimum lateral inflow. The lumped routing models in HEC-HMS assume that these volumes are equal.

The duration of the downstream hydrograph should be sufficiently long so that the total volume represented equals the volume of the upstream hydrograph.

The next step is to select initial estimates of the parameters. As with any search, the better these initial estimates (the starting point of the search), the quicker the search will yield a solution. Given these initial estimates of the parameters, the models can be used with the observed boundary conditions (upstream flow) to compute the output, the channel outflow hydrograph.

At this point, the program compares the computed hydrograph to the observed hydrograph. The goal of this comparison is to judge how well the model "fits" the real hydrologic system. If the fit is not satisfactory, the program systematically adjusts the parameters and reiterates. When the fit is satisfactory, the program will report the optimal parameter values. The presumption is that these parameter values then can be used routing computations that are the goal of the flood runoff analyses.

\subsubsection{Goodness-of-fit Indices}

To compare a computed hydrograph to an observed hydrograph, HEC-HMS computes indices of the goodness-of-fit. The three indices calculated are:

1. Mean Absolute Error (MAE).

2. Root Mean Square Error (RMSE).

3. Nash-Sutcliffe Efficiency cCoefficient (NSE).

$$
\begin{aligned}
& \text { MAE }=\frac{\sum_{1}^{n}\left|Q_{s i}-Q_{o i}\right|}{n} \\
& \text { RMSE }=\sqrt{\frac{\sum_{1}^{n}\left(Q_{s i}-Q_{o i}\right)^{2}}{n}} \\
& \text { NAE }=1-\frac{\sum_{1}^{n}\left(Q_{s i}-Q_{o i}\right)^{2}}{\left(Q_{o i}-\bar{Q}_{o i}\right)^{2}}
\end{aligned}
$$

Where

Qoi is the ith observed flow and Qsi is the ith simulated flow $\bar{Q}_{o i}$ is the average of the observed flow $\mathrm{n}$ is the number of data points

A lower MAE and RMSE will give a better fit and a better model performance, on the other hand, a higher NAE gives a better fit for the model (NAE is normally between 0 and 1 ). 


\subsection{RESULTS AND DISCUSSION}

\subsection{General Set-up of the Flood Routing Computations}

The Muskingum and lag routing methods have been applied to the 6 flood events of Klang river (Table 2) mentioned earlier and the results obtained were compared to the observed hydrographs at the outflow locations. This includes the processes of calibration and validation using computer program HEC-HMS.The calibration process is to optimize the routing coefficients using inflow and outflow hydrographs recorded at the gauging stations. After successful calibration, the average routing coefficients were used in the validation (verification) process using selected floods of different events. Results are presented in the sections as follows:

\section{a. Calibration Results}

This is a summary of the calibration results on optimized parameters of routing models and the goodness of fit indices for the observed and predicted hydrographs. Average model parameters are derived for use in validation runs.

\section{b. Validation Results}

This is a summary of the simulation runs using the model parameters determined from calibration runs to obtain hydrographs for the selected flood events and the goodness of fit statistical parameters.

c. Comparison of predicted and observed hydrographs for validation runs.

Hydrographs from verification runs are used to compare with observed hydrographs to see the goodness of fit of the predicted and observed hydrographs visually.

\subsection{Results from Calibration Runs}

Of the six flood events chosen for this study for Klang river, 3 are used for calibrating the routing models and the rest used for model validation. Calibration results for Klang river using Muskingum method are presented in Table 4.

Figure 6 shows the observed and predicted hydrographs for the 02/05/1974 flood for Klang river using Muskingam model.

Calibration results using Lag method for Klang river are presented in Table 5.

Figure 7 shows the observed and predicted hydrographs for the 02/05/1974 using Lag model respectively for Klang river.
Results show that the Muskingum method gives a better fit as it has overall better goodness of fit indices.

\subsection{Results from Validation Runs}

The average calibrated parameters of the routing models were used to predict the outflow hydrographs for 3 recorded floods

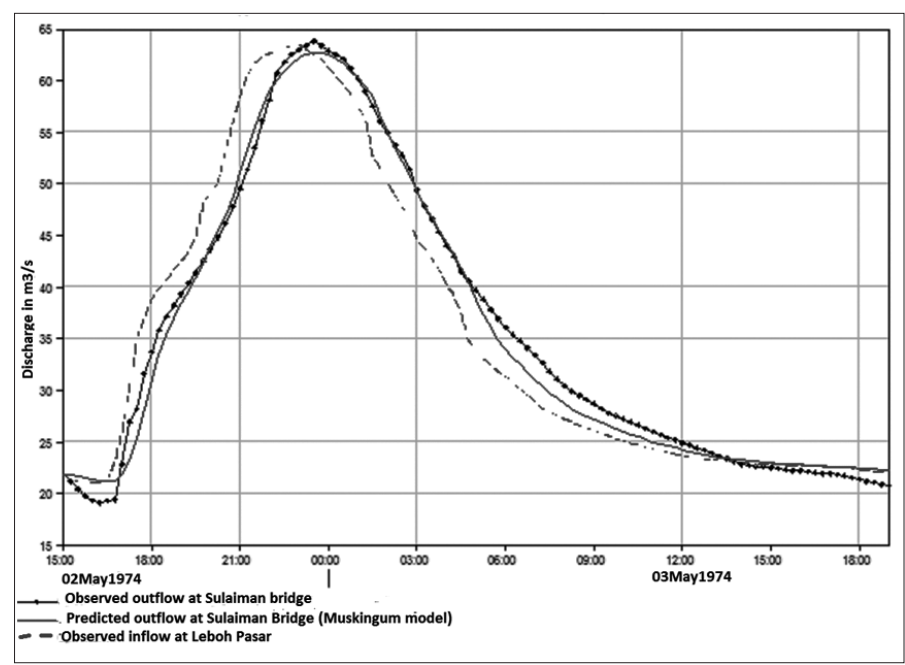

Figure 6: Observed inflow/outflow and predicted (Muskingum model) hydrographs of the 02/05/1974 flood, Klang river

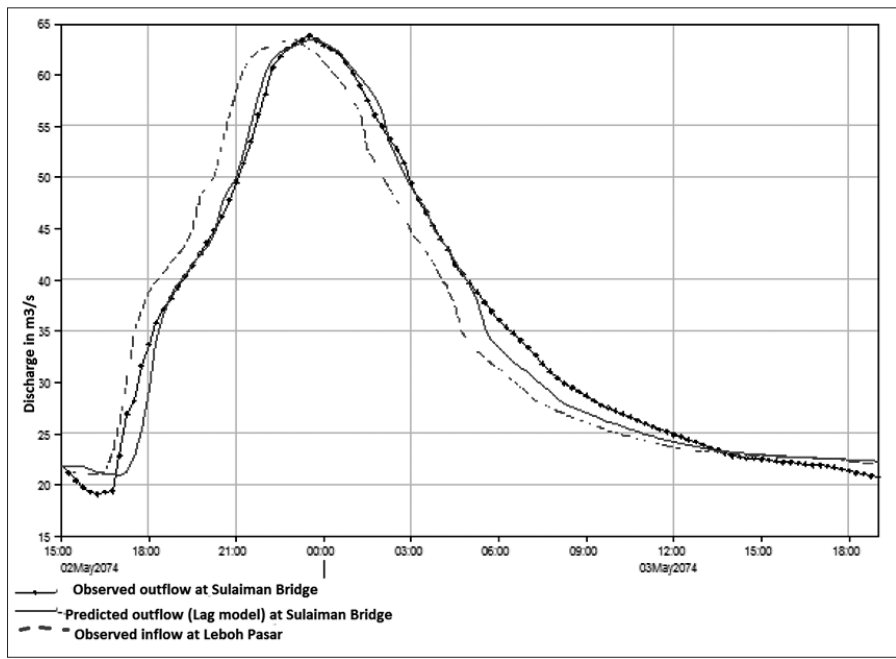

Figure 7: Observed inflow/outflow and predicted (Lag model) hydrographs of the 02/05/1974 flood, Klang river

Table 4: Calibration results for Muskingum model, Klang river

\begin{tabular}{|c|c|c|c|c|c|c|c|c|}
\hline \multirow{2}{*}{ Flood Occurred On } & \multirow{2}{*}{ K, hours } & \multirow{2}{*}{ No. of Subreaches } & \multirow{2}{*}{$\mathbf{x}$} & \multicolumn{2}{|c|}{ Peak Flow $\mathbf{( \mathbf { m } ^ { 3 } \mathbf { s } )}$} & \multirow{2}{*}{ MAE } & \multirow{2}{*}{ RMSE } & \multirow{2}{*}{ NAE } \\
\cline { 5 - 8 } & & & & Observed & Predicted & & & \\
\hline $02 / 05 / 1974$ & 0.8 & 1 & 0.142 & 63.8 & 62.7 & 1.1 & 1.3 & 0.992 \\
\hline $07 / 12 / 1974$ & 0.61 & 1 & 0.141 & 53.9 & 55.6 & 1.3 & 2.5 & 0.938 \\
\hline $06 / 12 / 1973$ & 0.61 & 1 & 0.142 & 151.3 & 189.5 & 5.7 & 9.2 & 0.935 \\
\hline Average & 0.68 & 1 & 0.142 & & & & & \\
\hline
\end{tabular}

Table 5: Calibration results for Lag model, Klang river

\begin{tabular}{|c|c|c|c|c|c|c|}
\hline \multirow{2}{*}{ Flood Occurred On } & \multirow{2}{*}{ Lag (minutes) } & \multicolumn{2}{|c|}{ Peak Flow $\left(\mathbf{m}^{\mathbf{3}} / \mathbf{s}\right)$} & \multirow{2}{*}{ MAE } & \multirow{2}{*}{ RMSE } & \multirow{2}{*}{ NAE } \\
\cline { 3 - 6 } & & Observed & Predicted & & & \\
\hline $02 / 05 / 1974$ & 48 & 63.5 & 63.8 & 1.1 & 1.6 & 0.987 \\
\hline $07 / 12 / 1974$ & 123 & 53.9 & 196.3 & 2.9 & 5.8 & 0.664 \\
\hline $06 / 12 / 1973$ & 24.5 & 151.3 & & 5.7 & 9.1 & 0.935 \\
\hline Average & 65 & & & & \\
\hline
\end{tabular}




\section{MUSKINGUM AND LAG METHOD RIVER ROUTING PARAMETERS FOR KLANG RIVER AT KUALA LUMPUR CITY CENTRE DERIVED USING RECORDED HYDROGRAPHS}

Table 6: Validation runs for Muskingum method, Klang river

\begin{tabular}{|c|c|c|c|c|c|c|c|c|}
\hline \multirow{2}{*}{ Flood Occurred On } & \multirow{2}{*}{ K, hours } & \multirow{2}{*}{ No. of Subreaches } & \multirow{2}{*}{$\mathbf{x}$} & \multicolumn{2}{|c|}{ Peak Flow $\left(\mathbf{m}^{\mathbf{3}} \mathbf{s}\right)$} & \multirow{2}{*}{ MAE } & \multirow{2}{*}{ RMSE } & \multirow{2}{*}{ NAE } \\
\cline { 5 - 8 } & & & & Observed & Predicted & & & \\
\hline $24 / 11 / 1973$ & 0.68 & 1 & 0.142 & 93.6 & 109.8 & 4.1 & 6.5 & 0.861 \\
\hline $10 / 12 / 1974$ & 0.68 & 1 & 0.142 & 70.8 & 68.4 & 2.2 & 3.4 & 0.957 \\
\hline $22 / 12 / 1973$ & 0.68 & 1 & 0.142 & 75.7 & 75.1 & 1.5 & 3.6 & 0.945 \\
\hline
\end{tabular}

Table 7: Validation runs for Lag method, Klang river

\begin{tabular}{|c|c|c|c|c|c|c|}
\hline \multirow{2}{*}{ Flood Occurred On } & \multirow{2}{*}{ Lag (minutes) } & \multicolumn{2}{|c|}{ Peak Flow $\left(\mathbf{m}^{\mathbf{3} / \mathbf{s})}\right.$} & \multirow{2}{*}{ MAE } & \multirow{2}{*}{ RMSE } & \multirow{2}{*}{ NAE } \\
\cline { 3 - 7 } & & Observed & Predicted & & & \\
\hline $24 / 11 / 1973$ & 65 & 93.6 & 6.8 & 4.7 & 7.8 & 0.8 \\
\hline $10 / 12 / 1974$ & 65 & 70.8 & 75.5 & 2.7 & 2.3 & 0.98 \\
\hline $22 / 12 / 1973$ & 65 & 75.7 & 5.2 & 0.888 \\
\hline
\end{tabular}

in Klang basin using Muskingum and Lag methods. Results of Muskingum method are shown in Table 6.

Figure 8 shows the observed and predicted hydrographs for the 10/12/1973 flood using Muskingam model for Klang.

The Lag model validation results are shown in Table 7.

Figure 9 shows the observed and predicted hydrographs for the 10/12/1974 flood using Lag model for Klang river.

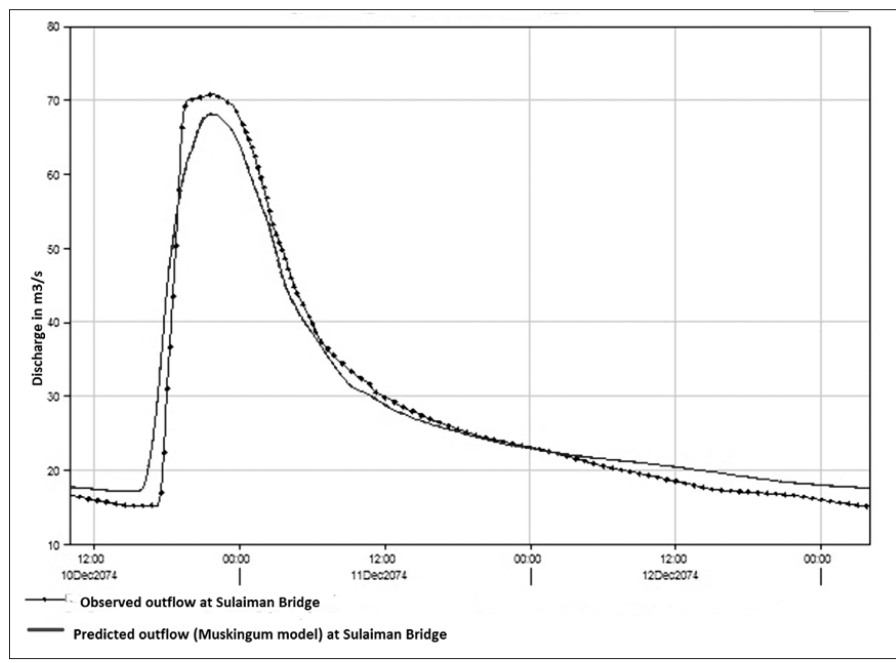

Figure 8: Observed and predicted (Muskingum model) outflow hydrographs of the 10/12/1974 flood, Klang River

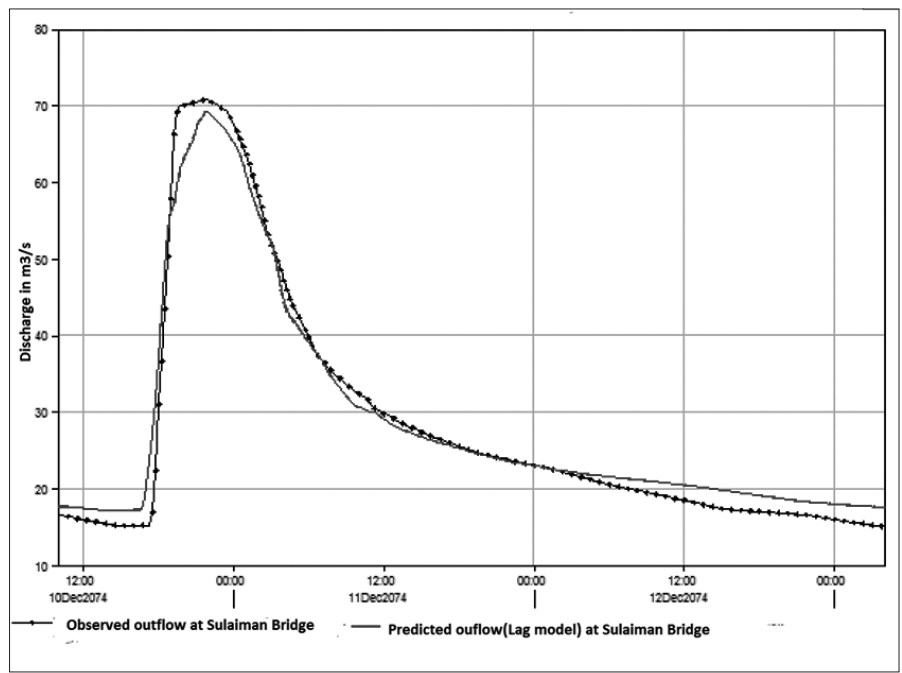

Figure 9: Observed and predicted (Lag model) outflow hydrographs of the 10/12/1974 flood, Klang River

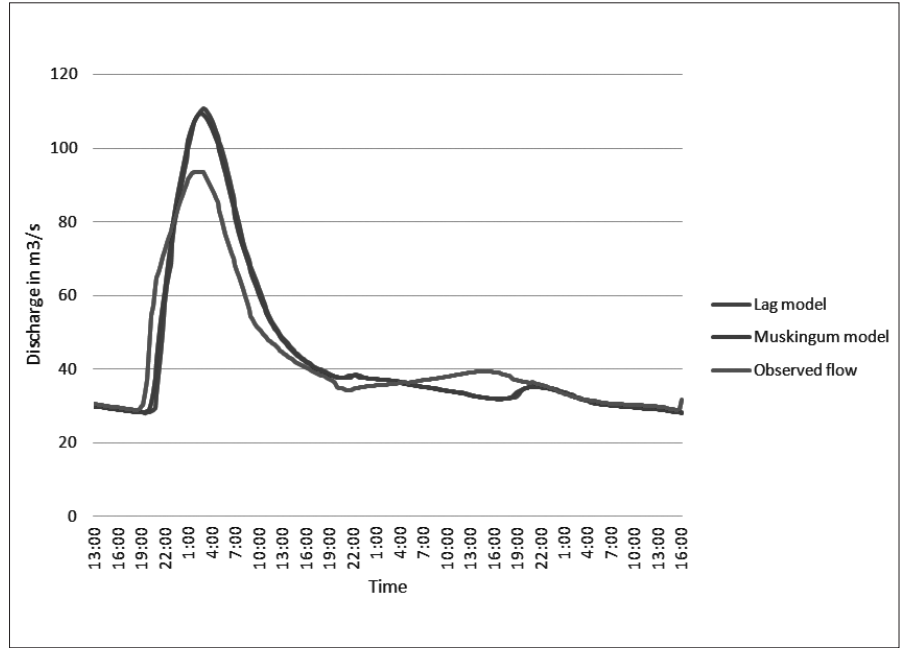

Figure 10: Recorded and routed hydrographs using Muskingum and Lag model at Sulaiman Bridge 24/11/1973 flood

Results show that the Muskingum method gives better predicted hydrographs as it has overall better goodness of fit indices obtained from the validation runs.

\subsection{Verification the Flood Routing Models with the Klang Flood Events}

In order to assess the ability of the routing models in reproducing the observed floods, the floods simulated in the validation runs of Klang river at the outflow gauging sites were used to compare with the observed floods. Details are presented as follows:

\section{a. The Klang 24/11/1973 Flood}

The corresponding hydrographs for the flood event are shown in Figure 10. The observed and calculated discharges at the reach outlet at Sulaiman Bridge for the two models are shown. From visual inspection of the hydrographs, the two routing models appear to be equally good. However, the goodness of fit test show that the Muskingum overall fits better than the Lag model. As stated by Zare[8], sharp rise events such as this flood are more difficult to predict using the kinematic wave type of models such as Muskingum and Lag routing methods.

\section{b. The Klang 10/12/1974 Event}

The second verification run of the routing models is based on the 10/12/1974 flood. The results are plotted in Figure 11. From graphical inspections, the hydrographs predicted from the two models are similar. The agreement with the observed 


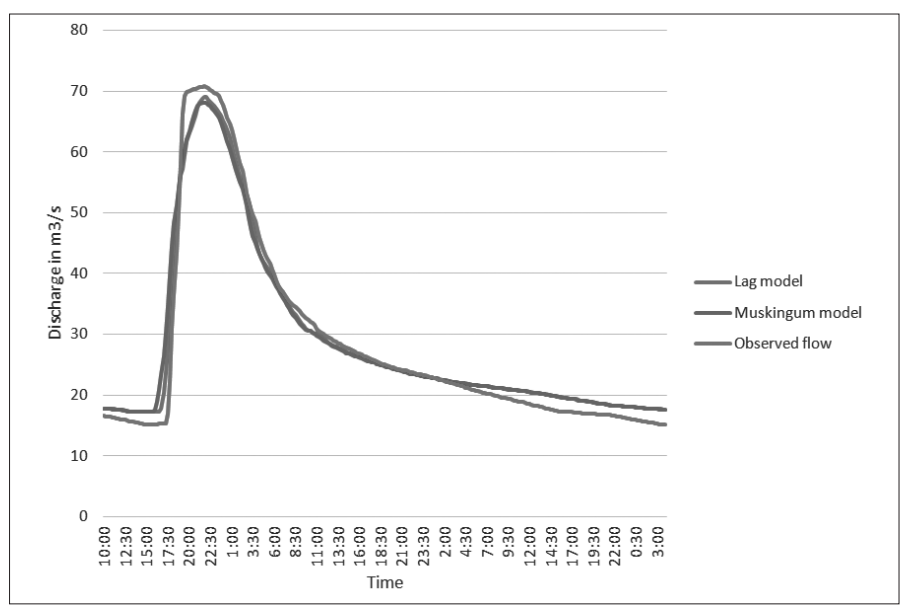

Figure 11: Recorded and routed hydrographs using Muskingum and Lag model at Sulaiman Bridge 10/12/1974 flood

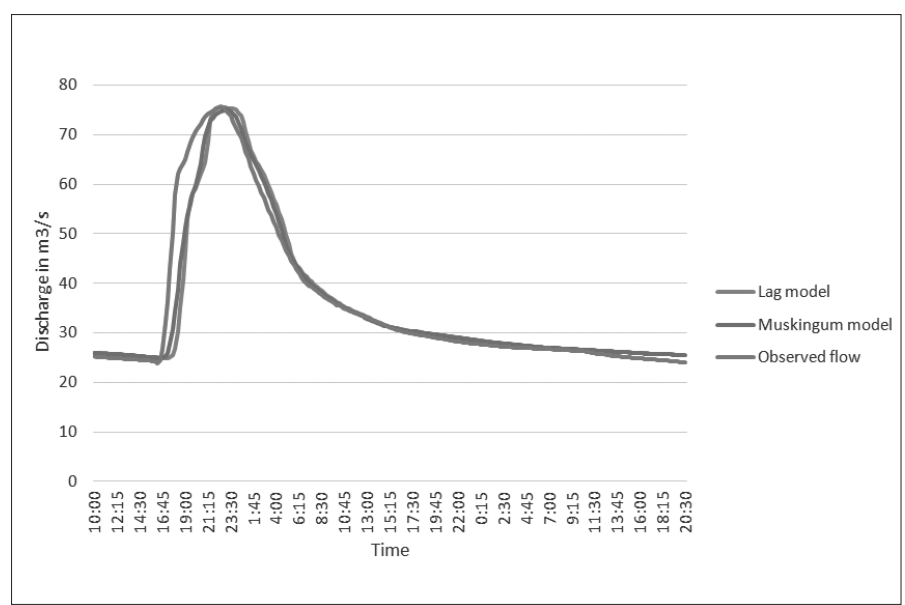

Figure 12: Recorded and routed hydrographs using Muskingum and Lag model at Sulaiman Bridge 22/12/1973 flood

hydrograph is also good. However, for this particular case, in terms of goodness of fit, the lag model performs better.

\section{c. The Klang 22/12/1973 Flood}

The third verification run of the routing models is based on the 22/12/1973 flood. The results are plotted in Figure 12. From graphical inspections, the hydrographs predicted from the two models are similar. The agreement with the observed hydrograph is also good except in the rising limb. However, in terms of goodness of fit, the Muskingum model performs better.

\subsection{CONCLUSION}

The objective of this paper is to use simple routing techniques to assess the applicability of the methods to Malaysian rivers. The Klang river in Peninsular Malaysia was selected for analysis, with a river length of $0.95 \mathrm{~km}$ and gauging records at both the upstream and downstream end of the reach. The performance of the methods was evaluated by comparing the simulated and observed hydrographs graphically and statistically. In graphical analysis, the routed hydrographs from Muskingum and lag models generally are congruent with the observed hydrographs. In the calibration and validation analysis, the Muskingum model usually gives better goodness of fit indices and it performs better than the Lag model for most of the flood hydrographs used for calibration and verification.

\subsection{ACKNOWLEDGEMENT}

The permission of Drainage and Irrigation Department to use the data for this study is gratefully acknowledged.

\section{REFERENCES}

[1] Hydrologic Engineering Centre (2016), Hydrologic Modeling System, User Manual.

[2] Cunge J. A. (1969) On the subject of a flood propagation computation method (Muskingum method) Jour. Of hydraulic research, 7.2, 205-230.

[3] Gill M. A. (1978) Flood routing by Muskingum method Jour. Of Hydrology, 36, 353-363.

[4] Mohan S. (1997) Parameter estimationof nonlinear Muskingum model using genetic algorithm Jour. Of hydraulic Engineering 123(2) 137-142.

[5] Tayfur G. and T. Moramarco (2007) Forcasing flood hydrographs at Tiber river in Italy by artificial neural network Int. congress on river management Antalya, Turkey, vol. II p 485-497.

[6] Hong J. L. and Hong K. A. (2016), Flood Forecasting for Klang River at Kuala Lumpur using Artificial Neural Network International Journal of Hybrid Information Technology Vol. 9, No. 3.

[7] Oladghaffari A., A.Fakheri Fard, A. H. Namazi and M.A. Ghorbani (2009) Hydrulic flood routing using dynamic wave method and comparison with linear and nonlinear Muskingum routing methods, Water and soil science journal 20, 3, 47-60.

[8] Zare M. and Koch M. (2013) An analysis of MLR and NLP for use in river flood routing and comparison with the Muskingum method, Proceedings of 2013 IHAR world congress.

[9] Ansari A. M. and Ukarande (2016), Calculating the Parameters of Muskingum Methods for a Rectangular Channel, Ied India vol. 3 Issue 3.

[10] Song X. M. Kong F. Z (2011), Application of Muskingum Routing Method with Variable Parameters in Ungauged Catchments Water Science and Engineering 4 (1).

[11] Kumar D. N. Raju K.S. (2011), Extended Muskingum Method for Flood Routing Journal for Hydro-Environment Research 5.

[12] Elbashir S.T. (2012), Flood Routing in Natural Channels using Muskingum Method.

[13] Reggiani P., Todini E., Meisner D. (2014), A Conservative Flow Routing Formula Muskingum Method Revisited Journal of Hydrology 519.

[14] Sajikumar N. A., Gyncy I. B., Sumam K. S. (2015), Modelling of Nonlinear Muskingum Method Using Control System Concept, Aquatic Procedia 4.

[15] Tewolde M. H. and Smithers J. C. (2006) Flood Routing in Ungauged catchments using Muskingum Methods, Water SA Vol. 32.

[16] Pilgrim D. H. and Cordery I. (1993), "Flood runoff", D.R. Maiddment Handbook of Applied Hydrology. 


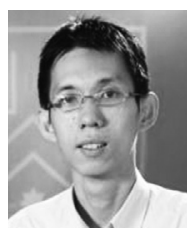

DAVID HONG JER LANG is currently a lecturer of Taylor's University, Malaysia. He received his B.Sc degree in computer science from Nottingham University in 2005 and the Ph.D. degree from Monash University in 2010. He is author and co-author of several Association for Computing Machinery/Institution of Electrical and Electronic Engineers (ACM/IEEE) conference papers and is also the author of several papers in automatic wrapper design published in computer science journals and is the co-author of the book "Hydrological Analysis and Design: An approach based on Malaysian Rainfall and Runoff". David Hong is listed in Who's Who in the World.

Email address: jerlang.hong @taylors.edu.my

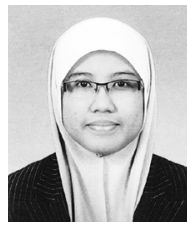

SUZANA BINTI SHAFIE obtained her Bachelor Degree in Civil Engineering from University Teknologi Malaysia (UTM) in 2007. Suzana joined G\&P Water and Maritime Sdn. Bhd. in 2008 and she is now associate and Chief hydrologist of the firm. She is actively involved in flood and yield studies and currently her major role is on flood and low river flow and reservoir operation projects mainly on the research prospects.

Email address: suzana_peace@yahoo.com

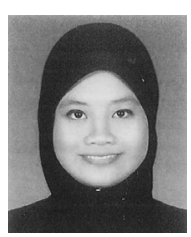

IRENA BINTI NAUBI received her Bachelor's Degree and Master's Degree from Universiti Teknologi Malaysia (UTM). She is currently working as an engineer in G\&P Water \& Maritime Sdn. Bhd. and involved in hydrology projects such as development of hydrological procedure and dam operational studies.

Email address: irena.naubi@gmail.com

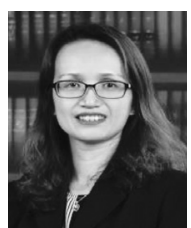

YONG SIEW FANG is currently the Director of Hydrology in G\&P Water \& Maritime Sdn. Bhd. She obtained the Bachelor of Civil Engineering degree (Civil-Environmental) from Universiti Teknologi Malaysia in 2000. Ir. Yong has more than 20 years of experience in flood mitigation and water resources studies, and the management of flood mitigation and water control projects.

Email: siewfang_yong@yahoo.com

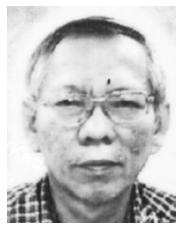

HONG KEE AN is presently a consultant in hydrology and water resources and he worked as a hydrologist, water resources planner and modeler for various water supply projects in Malaysia. He received his B.Sc. degree in Agricultural Engineering from National Taiwan University in 1971 and the M. Eng. degree in Water Science from Asian Institute of Technology in 1973. He is the author of several papers published in the journal and bulletins of the Institution of Engineers, Malaysia and Malaysian Water Work Association and the books" A Guide to Flood and Yield Estimation" and "Hydrlogical Analysis and Design: An approach based on Malaysian Rainfall and Runoff". He is a Fellow of the Institution of Engineers, Malaysia and is listed in Who's Who in Engineering published by the American Association of Engineering Societies.

Email address: keeanhong@yahoo.co.uk 